\title{
Drivers and challenges of electric vehicles integration in corporate fleet: An empirical survey
}

\section{Abstract}

Low-carbon economy roadmaps aim to reduce transport emissions by relying, at least to some extent, on electric vehicles. The uptake of electric vehicles on a mass scale requires the simultaneous adoption of such vehicles for private and commercial purposes. Although literature regarding the private sphere is consistent, there is comparatively less empirical research seeking to explain the factors that enable and hinder the uptake of electric vehicles at a commercial level at which fleet managers have a prominent role. Based on an empirical survey conducted in Italy, this paper investigates the role of technical and financial information in fleet managers' procurement decision-making. Results suggest a lack of awareness regarding technical characteristics of vehicles, given that $59 \%$ of the fleet managers surveyed scored low to medium. Furthermore, a misalignment related to the expected investment payback period was observed, considering that $49 \%$ declared that they expect a payback period within three years. Given that exposure to electric vehicles within fleets constitutes an incentive for private purchase, well-designed policies for corporate fleets' electrification would lead to remarkable growth of the electric vehicles market.

Article information: preprint

Citation

https://doi.org/10.1016/..rtbm.2021.100627 


\section{Introduction}

Following the international treaty on climate change adopted by 196 parties in Paris, governments worldwide have pledged to act against climate warming. For example, the European Union has committed to reducing its total emissions to at least 40 percent below 1990 levels by 2030 and to reducing transport emissions by more than 60 percent by 2050. Given the challenges facing the path to decarbonization, the environmental performance of the transport sector must improve soundly considering that this sector is responsible for more than a quarter of the carbon emissions from fuel combustion. Given that the demand for mobility will continue to grow in the coming decades, measures are required in the short term as fossil fuels currently cover $92 \%$ of the sector's needs (Santos, 2017). Although several initiatives have been initiated worldwide to promote electric mobility, several challenges persist; in this respect, a recent paper predicts that in the next two decades, electric vehicles (EVs) will account for a share of between $11 \%$ and $28 \%$ of the global road transport fleet (Kapustin \& Grushevenko, 2020). It is understood that the share of EVs will depend on industry investments in vehicles and infrastructure and on organizations that add EVs to their fleets (Vehmas et al., 2018). In this respect, significant benefits for industry, customers, and society from investments in EVs (Dillon et al., 2020) have been identified, such as a reduction in local emissions.

Although the literature abounds in articles related to the impact of electric mobility on transport sector sustainability (Baptista et al., 2014; Hawkins et al., 2013; Seign et al., 2015), the role that corporate fleets play in decarbonization deserves more attention because vehicle fleets are one of the largest sources of greenhouse gas emissions for many companies. This is particularly true due to the increasing number of corporate vehicles, the incentive for private purchase that employees' exposure to EVs within fleets represents, and the technology developments that contribute to cutting costs.

Fleet managers carry out management activities related to the fleet owned by an organization, in which vehicle-related costs can account for a significant proportion of costs. Indeed, in the increasingly complex business arena, fleet managers work closely with other key departments to support the organizations' strategy for sustainability. However, although corporate fleets are considered early adopters of EVs (Sierzchula, 2014), their electrification course remains slow. This is partly due to obstacles typical to EV adoption, 
such as range anxiety, limited infrastructure, and availability of models (Globisch, Dütschke, \& Schleich, 2018; Li et al., 2017).

Within corporate greening strategies, fleet managers are increasingly included in the decision-making process aimed at implementing electric fleets. Decision-making based on imperfect information is however risky because it increases the likelihood of strategic slipups. Indeed, in dynamic industries, fleet managers must make the right strategic choices while additionally performing their main activities and looking to the future of the market they operate in (Giones et al., 2019). This article focuses on the role that information plays in decision-making regarding EV adoption, particularly the prominent role of technical understanding and economic awareness. Technical understanding refers to technical knowledge concerning three types of EVs: battery EVs, plug-in hybrid EVs, and hybrid EVs, while economic awareness represents the expectations in terms of payback on, investments given that fleet managers are usually responsible for strategic planning.

It is argued that the combination of fleet managers' commitment to increasing the share of EVs in the fleets they manage, and effective policymaking, can bring about socioeconomic and environmental benefits (Yokessa \& Marette, 2019). Indeed, according to the International Council on Clean Transportation, there is a causal link between the increase of EVs in fleets and the increase in EV adoption by citizens (Jin \& Slowik, 2017). This causal link derives from the fact that fleets directly provide potential buyers significant exposure to these vehicles, thus representing an opportunity to try out such vehicles during work.

Previous research has shown that market failure hinders investment in sustainable technology (Egnér \& Trosvik, 2018). Other market contributing to market failure include the gap between the expected and actual payback period, imperfect technical information and knowledge, ineffectiveness of incentives, limited economies of scale, and compromise between investments for efficient energy and other priorities (IEA, 2017). This article pays particular attention to the need to overcome the misalignment between expected and actual payback time and the need to enhance understanding of vehicles' technical characteristics.

The analyses in this paper were based on a survey through which empirical data were gathered via a five-month research project involving the participation of 293 fleet 
managers who filled out an online questionnaire. A survey of 364 UK-based commercial and public sector fleet buyers was completed with the aim of identifying personal and organizational factors that might encourage fleet managers to purchase EVs.

The remainder of this paper is organized as follows: Section 2 reviews the main research topics considered in this article. Section 3 presents the research design, and section 4 outlines the main results, which are discussed in section 5 . Conclusions follow in Section 6 .

\section{Literature}

The need for transport decarbonization has prompted new business opportunities; in this respect, previous literature on business models has highlighted ways in which competitive advantage may be safeguarded by creating new businesses or by reorganizing existing ones (Budde Christensen et al., 2012). In the current economic context, companies face the challenge of transforming sustainability into a source of economic value creation given that appropriate business models bring competitive advantages (Bohnsack et al., 2014). Specifically, adequate business models can increase competitiveness through the integration of green technologies available on the market.

These arguments have recently become more important than in the past as the need for including innovations in business models has received widespread attention (Chesbrough, 2010). A manifest obstacle to the innovation of business models is the so-called path dependence-i.e., the mechanism by which current and future decisions depend heavily on former decisions: it entails positive feedback mechanisms that push towards rigidity over time (Gärtner \& Schön, 2016). With regard to sustainable mobility, innovations in business models alone struggle to drive significant changes; in this context, an innovative business model that includes EVs may still fail in the face of entrenched practices (Budde Christensen et al., 2012).

In addition to considering business models, it is important to refer to some of the factors that influence fleet managers' decision-making processes. From a broad perspective, a number of articles have considered factors that influence the adoption of EVs (Junquera et al., 2016; Wang et al., 2018). In addition to costs, which represent the best-known factor, other socioeconomic factors are involved in the decision-making process, such as 
environmental awareness, disposable income, the number of charging stations, mobility needs, related services, subjective preferences (Yan, 2018), and incentives. Furthermore, environmental benefits and perceived ease of use have contributed significantly to explaining the adoption of EVs (Globisch, Dütschke, \& Wietschel, 2018). Another study suggested that fleet managers consider safety to be very important (Zhang et al., 2018). Likewise, the desire to test new technologies is a strong driver of EV adoption, and this desire has a similar level of importance to that of tax incentives and reputation due to the organization's image.

Innovation diffusion models are useful for modeling the evolution of technology use over time and through groups, especially as confirmed in the social-technical study. The spread of electric mobility is dependent on the competition between innovative actors (Marletto, 2014). The distribution of the process of adopting new technologies depends on the share of adopters who are innovators, early adopters, first majority, late majority (who are typically skeptical about the adoption of technology), and latecomers (Rogers, 2004).

The technology adoption decision-making process follows various phases, including knowledge acquisition, persuasion, decision, implementation, and confirmation. Therefore, certain factors, such as relative advantage, compatibility, complexity, experience, and observability, are fundamental to the decision-making process (Chiyangwa \& Alexander, 2016). In this article, relative advantage corresponds to the opportunity cost of the investment. Compatibility represents fleet managers' perceptions of investment opportunity and technology and whether these two elements fit with business needs; complexity refers to assessment of the technological characteristics of EVs available on the market. Experience pertains to the possibility of testing the available technology, which corresponds to the fleet (Jin \& Slowik, 2017). Finally, observability corresponds with the social influence derived from the contact fleet managers have with peers from other companies. In practice, fleet managers make decisions based on their experience and business strategy, but are also influenced by colleagues or business partners (Ritala et al., 2014).

Electric vehicles can enable society to progress from the era of conventionally fueled vehicles, provided that the electricity used by them is not produced by polluting procedures that may create similar problems but based on cleaner energy generation (Kougias et al., 
2019, 2020). This is particularly true given that according to recent results, environmental performance surpasses price value and range confidence which represent well-known barriers to EV market development (Cassetta et al., 2017; Degirmenci, \& Breitner, 2017).

Corporate vehicle providers have expanded their EV offerings in recent years. However, companies struggle to invest in this technology because investment decisions are usually associated with uncertainty around the cost-benefit ratio. Fleet managers are not always able to adequately assess the conflict criteria and find suitable solutions. Compared with scientific work on supplier selection, the literature on evaluating and selecting green suppliers is still relatively scarce (Govindan et al., 2015). The choice of technology is guided by the interaction between many factors, including legislation, business strategies, interests, and related operational circumstances.

Consequently, the adoption of EVs results from interactions between variables such as technical characteristics, business activities, skills, market resources, and knowledge (Xia et al., 2019). Because much of fleet managers' work is supported by information technology, the efficiency of services and of their work often depends on how the technology is used (Walczuch et al., 2007). If fleet managers can optimize technology selection based on supplier type, they can fine-tune their business models and improve the profitability of a selected technology (Cagno et al., 2018).

Payback time is the time needed to recover investment costs by the cash flow due to the investment (Di Foggia \& Beccarello, 2018; Qiu et al., 2015) and it is anticipated that most fleet managers are attracted to the procurement of EVs if the investment payback is up to three years. Although investment in new technologies may have a relatively short payback time because of operational improvements and efficiency (McHenry, 2013), there is still uncertainty about maximizing the benefits of investments. Clearly, the transition to EVs can have important repercussions on business organization in the context of logisticsrelated issues; in this respect, scholars carry out simulations to increase the information available to those responsible for making choices regarding company fleets. For example, a recent study analyzes the transition of a company's fleet, which currently consists of combustion vehicles, to EVs in order to understand how the electrical system will be affected by the installation of recharging stations (Pinto, et al., 2020). 
Recent studies suggest that there is a general lack of knowledge and awareness about EVs; for instance, about two-thirds of respondents of a survey were not knowledgeable about EVs' characteristics, and almost none were aware of the scope of available incentives (Jin \& Slowik, 2017; Krupa et al., 2014). However, it has been shown that knowledge of EVs drives car choice; however, the degree of knowledge does not change the perception respondents have of EVs. Moreover, the level of knowledge influences the importance placed on the attributes of the choice model (Giansoldati et al., 2020).

A recent study found that the variables that most influence the payback period on purchases of EVs are fuel price and financial incentives (da Silva et al., 2018). As is known, the purchase price of EVs is considered an obstacle to the adoption of EVs (Kinnear et al., 2017). A recent study based on an empirical survey states that more than $80 \%$ of respondents considered purchase price as crucial when considering the purchase of EVs, even if lower running costs compared with conventionally fueled vehicles are confirmed to be a driver of EV selection. According to the study, respondents were willing to pay a higher price if the payback time associated with running-cost savings was limited to 4.7 years. This implies that the expected payback time of fleet managers surveyed in this paper is, in many cases too short: this may pose an obstacle to EV adoption at a corporate level, ceteris paribus. Similarly, another study developed a total cost of ownership model to assess the payback period (Al-Alawi \& Bradley, 2013). Nevertheless, $65 \%$ of the 500 surveyed fleet managers agreed that introducing EVs could help their business as a whole meet sustainability targets (Daina, 2020). Another study confirmed that the number of charger points, fuel price, and road priority support the uptake of EVs to the same extent as fiscal incentives do, which are no longer central reasons for the considerable differences in EV promotion in different countries (Wang et al., 2019). Figures change according to types of incentives, including value added tax, one-time purchase/registration tax, circulation tax, and corporate tax (Nie et al., 2016).

\section{Research design and data}

The design of this study comprises a survey preceded by face-to-face in-depth interviews of members of a panel to design the questionnaire. The target respondents were professionals in fleet management, who were surveyed to learn more about EV integration in corporate 
fleets. The analyses in this paper were based on data gathered via a five-month research project with the participation of 293 fleet managers who filled out an online questionnaire. A similar sample and research goal can be found in Bennett (2015), which is based on a survey of 364 UK fleet managers with the aim of identifying personal and organizational factors that might encourage them to purchase EVs. To the same token, Globisch, Dütschke, and Wietschel, (2018) highlighted the factors that motivate fleet managers to campaign for EVs, based on a sample of 229 fleet managers. According to the authors, a personal interest in EVs strengthens the intention to launch procurement initiatives, given that perceived environmental benefits foster the individual adoption of such initiatives.

\section{a. Survey and questions}

The structure and organization of this research were derived from a literature review. In fact, as previously mentioned, the number of scientific publications concerning the adoption of EVs by operators is increasing. However, this paper goes further and aims to verify related aspects: the correlation between expected and actual payback time and an understanding of the technical characteristics of EVs. Based on findings from a focus group, we identified the need to examine fleet managers. As a result, a survey emerged as the pillar of this research. Fleet managers who participated in this research were responsible for both passenger and freight operations, given that both type of fleet were found suitable for inclusion in the sample.

The survey covered several aspects of the managers' activity. In the first section, questions related to the business context in which the fleet managers operate were posed so that the answers could be considered in light of the context of reference. In addition to questions related to the business context, the survey contained questions aimed at classifying respondents on the basis of their business role and certain demographic characteristics. The subsequent section related to services typically under the responsibility of fleet managers in order to verify what percentage of these services are provided by third parties.

Subsequently, the survey asked some questions designed to evaluate the importance of certain operations within the tasks that fleet managers carry out on a daily basis. In this way, it was possible to define questions that aimed to assess the importance of certain factors at the time of the survey and to anticipate the importance of the same factors for the coming years. Furthermore, the survey contained questions related to the percentage of 
EVs in the fleet, the expected payback time of the investment, and the technical characteristics of EVs in order to assess the fleet managers' understanding thereof. The logic of this approach was supported by the principle of triangulation (Hastings, 2010) to strengthen confidence in the results. In order to convert qualitative information into data, the questions were operationalized (Mueller, 2004). To allow respondents to state the extent to which they agreed with predefined statements or how often they performed certain tasks, answer ranges were classified from 1 to 5 using an evaluation scale (Brace, 2004). The scale properties were adapted based on the following values: (1) low or never, (2) medium-low or almost never, (3) medium or sometimes, (4) medium-high or often, (5) high or always.

The survey was designed to answer the following research questions (RQs), clustered in two fields. The first is the information field that comprises RQs from 1 to 3 . The second is the operational field that consists of RQs 4 and 5, which represent the core of our research:

RQ1: Will the share of EVs in fleets increase in the coming years? This question was particularly important to understand whether the mobility electrification trend also occurs at the corporate fleet level.

RQ2: Do fleet managers appropriately assess and appraise themselves of the technological characteristics of EVs? This question was designed to test the fleet managers' understanding of the technical features of EVs available on the market.

RQ3: What is the expected repayment time for investments in sustainable mobility technologies? This question was asked because the opportunity cost of investments in EVs is known to depend on the time of return on the investment.

RQ4: Which factors, among the ones included in the survey, will become more important in the next five years? Predicting the main tasks in the near future can help in the decision-making process concerning EVs.

RQ5. Which services related to EVs do fleet managers outsource most? The phenomenon of servitization is accelerating, which is also attributable to new tools and technologies that make it possible to provide increasingly effective and efficient services capable of making investments more attractive. 
Data were acquired using a questionnaire that contained instructions for the respondents to follow in order to ensure that they completed it correctly (Yin, 2014). The questionnaire design to collect data followed common practices regarding the types of questions, the time required for completion, and other practices related to language (Couper, 2008). The datacollection campaign was conducted in collaboration with the editorial staff of a professional industry magazine, in line with data protection laws. The data-collection phase lasted five weeks, during which two e-mails were sent, and, in some cases, the fleet managers were also contacted by telephone.

The focus group confirmed the questionnaire's adequacy. The questionnaire was then sent as a pilot to three companies. Subsequent to this, the actual campaign was launched. The questionnaire was designed to ensure adequate clarity, ordering, and effectiveness of the questions. In partnership with the magazine mentioned above, electronic invitations to complete the online questionnaire were sent via e-mail to the sampling frame, which comprised 1,352 recipients. Recipients were invited to participate in the research in compliance with applicable legislation regarding privacy settings. Among 1,352 recipients who received the invitation to participate in the research, 373 started to fill the questionnaire, of whom 93 completed the questionnaire. Therefore, 93 respondents were considered participants; this figure corresponds to a $6.87 \%$ response rate.

Given that the paper relies on 93 surveys, the number of participants is relatively small; therefore, it is acknowledged as a limitation of the present study. For a comparison of factors affecting the uptake of EVs in Europe, see Christidis and Focas (2019). Their article confirms that the propensity to purchase an EV is correlated to income, the level of education, and the level of urbanization. It further argues that a little investigated factor in the literature, namely local conditions, is decisive when it comes to the decision to opt for an EV.

With regard to the respondents' roles, $54.83 \%$ of the interviewees were fleet managers; of these, $31.1 \%$ worked in facility services while $24.7 \%$ worked in the purchasing department. There is no information regarding the kind of vehicles they manage, e.g., automobiles, light commercial vehicles, medium-duty vehicles, or heavy-duty vehicles, to name a few; the same figure as per the economic activities of the companies. Table 1 provides a breakdown of the roles and departments of the 93 fleet managers that participated in the survey. 


\begin{tabular}{lcccccc}
\hline \multicolumn{7}{c}{ Department } \\
\hline Role & Administration & Facility services & Human resources & Other & Purchase & Total \\
Employee & 8 & 7 & 7 & 1 & 12 & 35 \\
Manager & 8 & 20 & 11 & 4 & 8 & 51 \\
Top manager & 1 & 2 & 0 & 1 & 3 & 7 \\
Total & 17 & 29 & 18 & 6 & 23 & 93 \\
\hline
\end{tabular}

Source: own elaboration

Table 1: Role and business unit

Almost two-thirds of the respondents (63.44\%) were male, and $75.2 \%$ of those interviewed had professional experience for a duration of between three and 10 years. From a crosscomparison of Table 1 and Table 2, it is evident that the respondents comprised professional figures with key responsibilities, including both operational and strategic functions. The fleet managers play an increasingly important role in the transition towards a sustainable mobility system.

\begin{tabular}{lccc}
\hline Years of experience & Female & Male & Total \\
\hline $0-2$ & 1 & 4 & 5 \\
$3-5$ & 9 & 17 & 26 \\
$6-10$ & 11 & 23 & 34 \\
$11-15$ & 8 & 9 & 17 \\
$>15$ & 5 & 6 & 11 \\
Total & 34 & 59 & 93 \\
\hline
\end{tabular}

Table 2: Gender and experience

Further important information on the sample derives from the businesses' characteristics in terms of their number of employees: $62.8 \%$ of the companies had more than 250 employees. In regard to fleet size, $34.5 \%$ of respondents had a fleet of $76-250$ vehicles (38.7\% had up to 75 vehicles and $26.8 \%$ more than 750 vehicles). Regarding fleet ownership, most (54.84\%) leased their vehicles, followed by both owning and leasing (34.41\%), and owning only (10.75\%). Referring to figure 1, three types of EVs were considered: battery EVs, plug-in hybrid EVs, and hybrid EVs. Fleet managers were asked to rank their knowledge regarding the following characteristics: combustion engine, electric motor, tailpipe emissions, electric battery power storage, cost of charge, length 
time to full charge, autonomy, the possibility of charging at charging points, regenerative breaking, and the possibility of charging at firm's premises. This was carried out to verify the relationship between knowledge of technological aspects and propensity to consider EVs, given that this is an often-neglected factor that deserves more attention.

\section{Results}

This section outlines the notable results that are useful for answering the research questions. The results suggest a lack of information and awareness regarding EVs in terms of technical characteristics, given that $59 \%$ of the fleet managers surveyed scored low to medium. Furthermore, the findings indicate a misalignment related to the expected investment payback period, considering that $49 \%$ declared that they expect a payback period of under three years.

The concept of relative advantage represents the opportunity cost of investing in EVs. Compatibility refers to the perception that fleet managers have towards investment and technology. Complexity pertains to the understanding of the technical characteristics of EVs. In fact, the relative advantage, which we define in this article as investment payback time, is commonly identified as an obstacle to the adoption of EVs. This section also presents information regarding the compatibility of EVs with corporate strategy, which is fundamental in making decisions and obtaining information regarding the complexity deriving from the fleet managers' ability to evaluate the market's technology. This ability to evaluate is essential to select the best technology, which impacts the opportunity cost. To select the best available technology, it is necessary that fleet managers have access to complete information and can interpret such information correctly.

The results also provide evidence regarding the typical contracts that the fleet managers manage in order to identify possible ancillary services. We also present findings on the main service activities that fleet managers carry out, and how these activities will evolve in the coming years. Finally, we provide estimates regarding the percentage of EVs in fleets in the coming years.

An independent group t-test was performed to check whether the company's size influences the payback period and technical knowledge (information). A t-test was conducted to compare means of the same variable between two groups. The payback time 
between the group of large companies (>250 employees) and small-medium companies, also known as SMEs ( $\leq 250$ employees), was compared, assuming that variances for the two populations were the same. In this case, the t-statistic was 0.262 with 91 degrees of freedom, and the corresponding two-tailed p-value was 0.7943; therefore, the difference of means in the payback period between large companies and SMEs is not different from 0. Subsequently, the technology knowledge (information) of large companies was compared versus that of SMEs, assuming that variances for the two populations were the same. In this case, the t-statistic was 0.896 with 91 degrees of freedom, and the corresponding twotailed p-value was 0.373; thus, the difference of means in technology knowledge between large companies and SMEs did not differ from o.
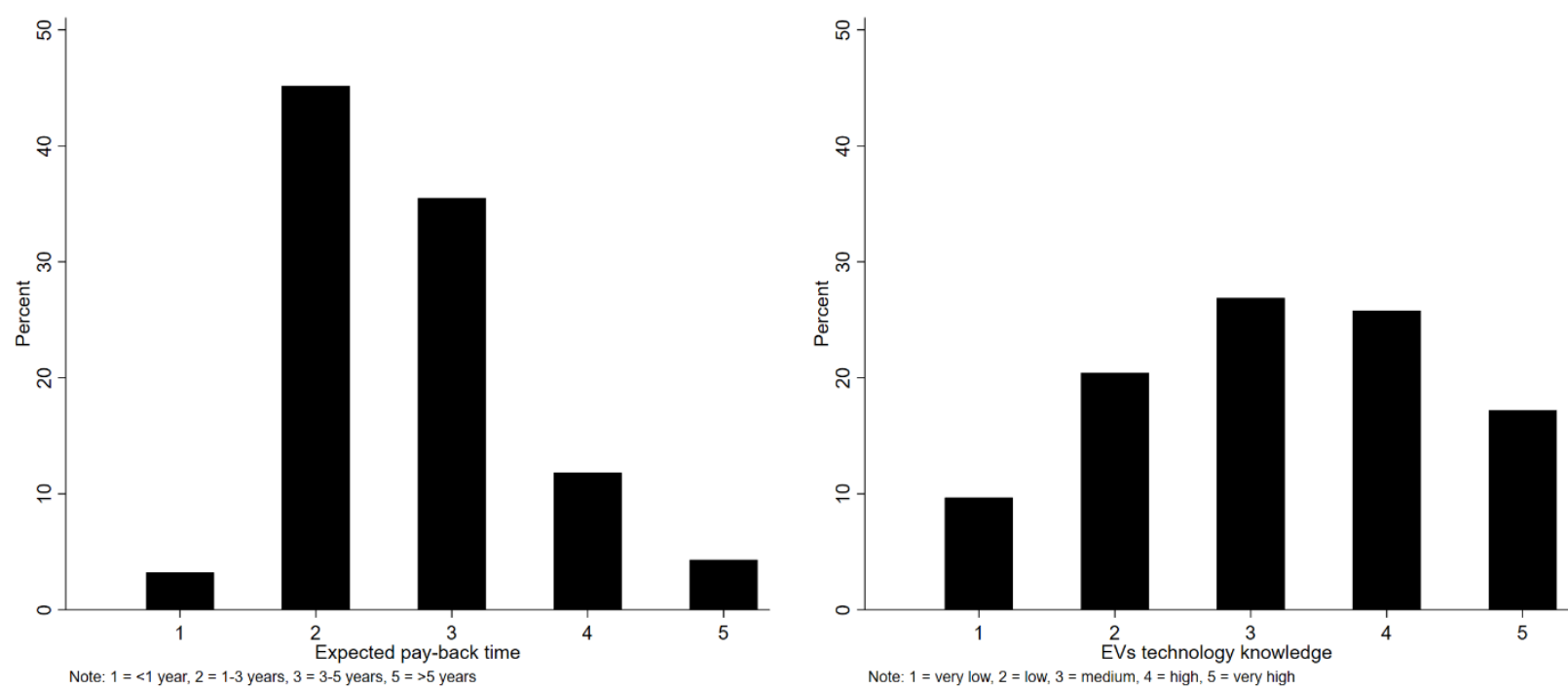

Source: own elaboration

Figure 1: pay back and imperfect tech information

The left quadrant of Figure 1 shows the frequency distribution related to the expected payback time of the investment. It shows that almost $49 \%$ and $84 \%$ of surveyed fleet managers indicated an expected payback time of up to three years and up to five years, respectively. The right quadrant of Figure 1 refers to technical aspects. The question contained an image of the three main technologies: battery EVs, plug-in hybrid EVs, and hybrid EVs, with some questions related to technical characteristics of vehicles . The respondents' frequency distribution of answers indicated a varied situation: about $30 \%$ said they had little understanding of EV technologies; this percentage is only slightly 
higher than the $27 \%$ who claimed to have average knowledge. Table 3 provides a summary of vehicle-related services that companies may outsource or manage in-house.

\begin{tabular}{lcc}
\hline & Outsource & In-house \\
& Percent & Percent \\
\hline Fleet maintenance & 91.57 & 8.43 \\
Roadside assistance \& replacement vehicles & 91.57 & 8.43 \\
Replacement vehicle & 83.13 & 16.87 \\
On-board safety tools and insurance & 73.49 & 26.51 \\
Fiscal and taxation management & 84.34 & 15.66 \\
Information services & 77.11 & 22.89 \\
Administration \& business operations & 39.76 & 60.24 \\
IT service for fleet management & 34.94 & 65.06 \\
Training and HR development & 28.51 & 71.49 \\
\hline Source: & &
\end{tabular}

Source: own elaboration

Table 3: Type of contracts with partners

Table 4 contains information regarding the factors that are expected to become more important in the next five years. From Table 4, three items seem to be of particular importance: data analysis and costing; the satisfaction of drivers; and the analysis of green technology.

\begin{tabular}{lllllll}
\hline & \multicolumn{3}{c}{ Current trend } & \multicolumn{3}{c}{ Outlook } \\
\hline Variables & Obs & Mean & Sd & Obs & Mean & Sd \\
\hline Procurement and services price negotiation & 88 & 3.61 & 1.33 & 91 & 3.84 & 1.32 \\
Quality evaluation of technology and services & 91 & 3.56 & 1.12 & 91 & 3.54 & 0.99 \\
Vehicles policies review & 90 & 3.61 & 0.97 & 91 & 3.87 & 0.95 \\
Economic and operational data analysis & 90 & 3.57 & 1.07 & 89 & 4.39 & 0.89 \\
ICT assessment & 87 & 3.16 & 1.26 & 89 & 3.57 & 1.23 \\
Fleet technology and risk analysis & 92 & 3.30 & 1.14 & 91 & 4.01 & 1.16 \\
Legal aspects of drivers-litigation & 92 & 3.55 & 1.19 & 93 & 3.51 & 1.19 \\
Dealing with drivers' satisfaction & 91 & 2.88 & 1.11 & 89 & 3.62 & 1.11 \\
Regulation compliance & 88 & 3.14 & 1.39 & 92 & 3.46 & 1.15 \\
Purchasing of technology for sustainability & 88 & 2.90 & 1.11 & 92 & 3.61 & 1.08 \\
\hline
\end{tabular}

Source: own elaboration

Table 4: Current and forward-looking importance

Fleet managers who indicated that they expect to see a growth in EVs in the coming years tend to deal with analytics and costing, fleet service quality checks, analysis of green mobility technologies, and drivers' welfare. Although the respondents recognized the increasing importance of technological issues, the benefits are still underestimated despite the fact that appropriately designed environmental regulation motivates firms to innovate, 
ultimately improving profitability (Rassier \& Earnhart, 2015; Rubashkina et al., 2014). On average, EVs represent 7.25\% (sd. 11.293) of the fleet, although this is expected to increase to $10.89 \%$ in the coming years (sd. 10.894).

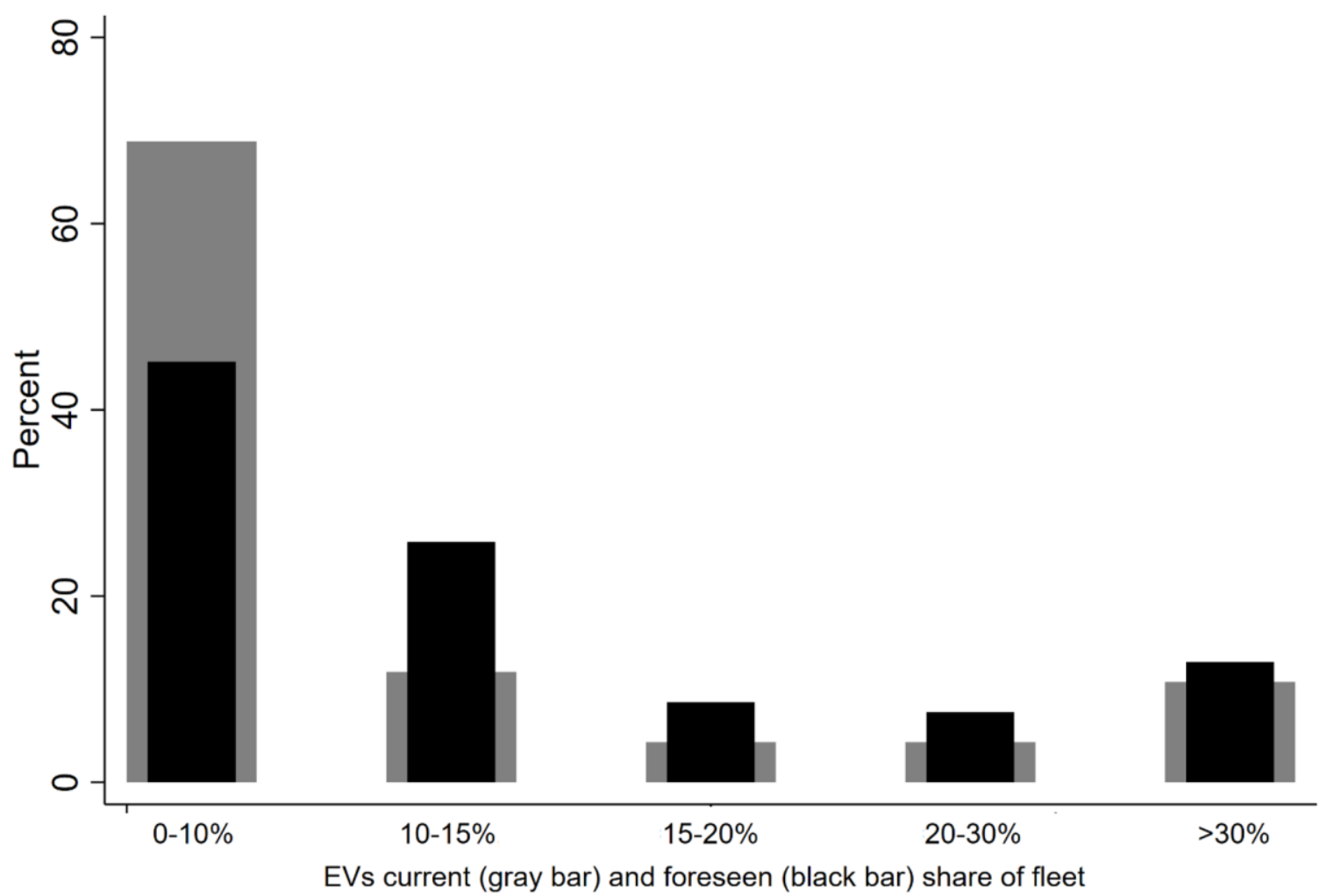

Source: own elaboration

Figure 2: Share of electric vehicles in the managed fleet

As shown in Figure 2, the proportion of respondents who indicated that the percentage of EVs among the total corporate fleet was less than 10\% decreased from around $70 \%$ to $44 \%$. In fact, there will be a significant increase in EVs; in particular, the band that undergoes the largest increase is the one that fluctuates between 10 and $15 \%$. On the one hand, this confirms the increasing trend in EV adoption; on the other hand, it suggests that the increase in such adoption will happen quite slowly.

\section{Discussion}

The results of this study reveal that the higher the number of corporate EVs, the higher the sales and usage by drivers who may otherwise not have had any knowledge of, or previous exposure to, EVs. Through these findings, this article strengthens knowledge on fleet 
managers' propensity toward EV adoption. In particular, $80 \%$ of fleet managers indicated that they would be willing to integrate electric cars into their fleets if they were offered tax incentives and partnerships with recharging infrastructure fleet managers.

Currently, however, the lack of information affects fleet managers' attitudes towards investments in EVs. Indeed, as shown in the results section, there is a lack of information and awareness regarding EVs in terms of their technical characteristics; further, we found a misalignment related to the expected investment payback period, considering that $49 \%$ declared that they expect a payback period of within three years. However, more than half of the respondents acknowledged that using EVs would positively reduce fleet costs. This is also supported by a recent study, which found that EVs have the advantages of low operating costs, low energy prices, and low maintenance costs. However, these advantages are offset by the higher cost relative to internal combustion vehicles, with rapid depreciation and additional battery costs (Lebeau et al., 2015). In the same token, this papers' results are consistent with those of a recent study that identified main barriers to EVs uptake: these include, to name a few, missing charging infrastructures, economic aspects, technical and operational restrictions, the well-known issue of low trust in EV autonomy, and information and knowledge (Biresselioglu et al., 2018). Therefore, it is becoming increasingly important to overcome the main barriers to the uptake of corporate EVs provided that the conditions to adopt the EVs vary between the users (Wikström et al., 2016).

An important requisite for the inclusion of EVs in corporate fleets is the positive impact of electric cars on corporate image. The main disadvantages identified by fleet operators were the short battery life, low number of the recharging points, high rental costs, long duration of the battery recharging process, and insufficient assistance services.

According to fleet managers, the share of EVs in corporate fleets will increase in the coming years; therefore, the trend of electrification of mobility will also take place at the level of corporate fleets. Nonetheless, there are gaps in understanding the technical characteristics of EVs available on the market. This may represent an underestimated barrier to EV uptake at the corporate level, given that, as shown in Table 1, fleet managers hold different business roles in their organization. Therefore, companies should invest in employee training so that they are able to make decisions under optimal conditions. In 
regard to the expected payback time for investments in sustainable mobility technologies, the results confirm that fleet managers expect the investment to be recovered over the short term, provided that environmental responsibility influences firm performance (Brekke \& Pekovic, 2018).

For this to take place, multi-year tax incentives are required to enable the investment to be more attractive than alternative investments. Regarding the factors that will acquire greater importance in the next five years, the results confirm that evaluation of, and investments in, technologies for sustainability will be important. Being aware of market trends is a key factor for maximizing revenues (Di Foggia \& Lazzarotti, 2014) and business performance. In this regard, it is worth considering that governments should support businesses by providing incentives to make EVs more attractive (Bakker \& Jacob Trip, 2013).

Given that the research approach is based on a questionnaire, the paper has some limitations with regards to the small size of the sample, which is limited to 293 respondents. A similar sample and research goal can be found in Bennett (2015), which conducts a survey of 364 UK fleet managers to identify personal and organizational factors that might encourage them to purchase EVs. In the same token, Globisch, Dütschke, and Wietschel (2018) highlight what motivates fleet managers to campaign for EVs, using a sample of 229 fleet managers. According to these authors, a personal interest in EVs increases the intention to launch procurement initiatives given that perceived environmental benefits foster individual adoption initiatives.

Other prominent topics that may be investigated are, to name a few, the effectiveness of EVs in meeting operational demands to support firms in order to determine whether EVs can represent a substitute for conventional fueled vehicles. To this end, it is crucial to understand if, and to what extent, EVs are reliable and would not cause downtime or impact the fleet managers' firms' operations. It is also important to rely on recent data on total cost of ownership of EVs to improve the information available to managers.

\section{Conclusions}

A promising way to reduce carbon emissions from transport is to increase the share of electric mobility and integrate it into the energy system, with an increasing proportion of 
renewable energy sources. Considering that companies will use different mechanisms to implement a sustainable fleet management strategy, a comprehensive green fleet management strategy must focus on the prioritization of EVs while investing in fleet managers' training on EVs technologies and economic issues. Indeed, the role that fleet managers may play in introducing EVs into commercial fleets has not received the deserved attention. This is the main contribution of this paper. Results of this study confirm that, according to fleet managers, the share of EVs in corporate fleets will increase in the coming years; on average, EVs represent $7.25 \%$ of the fleet, and this is expected to increase to $10.89 \%$ in five years from the time of this research. For the uptake of EVs at the corporate level to take place more rapidly, it is important to reduce the lack of information highlighted by the study findings. In particular, this includes enhancing fleet managers' understanding of the technical characteristics of EVs. Results also indicate that fleet managers expect their investment to be recovered in the short term-under three years in almost $60 \%$ of cases. Therefore, besides fiscal incentives to reduce the payback time, additional measures are needed to make investment in EVs more attractive. In fact, the opportunity cost of investments in EVs, which depends on th payback period for the investment e time of return on the investment, is still too high. Switching from the analyses to the operational level, three important items emerge as being particularly important: data analysis and costing, the satisfaction of drivers, and the analysis of green technology.

Given that there is a link between the increase in EVs in fleets and the increase in EV adoption by private citizens, businesses' policies and incentives will play an important role in increasing overall $\mathrm{EV}$ adoption. Indeed, exposure to $\mathrm{EVs}$ in fleets constitutes an incentive for private purchase that will lead to increased EV uptake, thus boosting a reduction in greenhouse gas emissions with consequent improvements in social health and wellbeing.

\section{Acknowledgements}

This research did not receive any specific grant from funding agencies in the public, commercial, or not-for-profit sectors. 


\section{References}

Al-Alawi, B.M., Bradley, T.H. (2013). Total cost of ownership, payback, and consumer preference modeling of plug-in hybrid EVs Applied. Energy, 103, 488-506, 10.1016/j.apenergy.2012.10.009

Bakker, S., \& Jacob Trip, J. (2013). Policy options to support the adoption of EVs in the urban environment. Transportation Research Part D: Transport and Environment, 25, 18-23. https://doi.org/10.1016/j.trd.2013.07.005

Baptista, P., Melo, S., \& Rolim, C. (2014). Energy, Environmental and Mobility Impacts of Car-sharing Systems. Empirical Results from Lisbon, Portugal. Procedia - Social and Behavioral Sciences, 111, 28-37. https://doi.org/10.1016/j.sbspro.2014.01.035

Bennett, R. (2015). Fleet vehicle buyers' intentions to purchase EVs: antecedents and possible consequences. International Journal of Electric and Hybrid Vehicles, 7(4), 362-374. https://doi.org/10.1504/IJEHV.2015.074677

Biresselioglu, M. E., Kaplan, M. D., \& Yilmaz, B. K. (2018). Electric mobility in Europe: A comprehensive review of motivators and barriers in decision making processes. Transportation Research Part A: Policy and Practice, 109, 1-13. https://doi.org/10.1016/j.tra.2018.01.017

Bohnsack, R., Pinkse, J., \& Kolk, A. (2014). Business models for sustainable technologies: Exploring business model evolution in the case of EVs. Research Policy, 43(2), 284300. https://doi.org/10.1016/j.respol.2013.10.014

Brace, I. (2004). Questionnaire Design. Business. London: Kogan Page.

Brekke, K. A., \& Pekovic, S. (2018). Why Are Firms Environmentally Responsible? A Review and Assessment of the Main Mechanisms. International Review of Environmental and Resource Economics, 12(4), 355-398. https://doi.org/10.1561/101.00000105

Budde Christensen, T., Wells, P., \& Cipcigan, L. (2012). Can innovative business models overcome resistance to EVs? Better place and battery electric cars in Denmark. Energy Policy, 48, 498-505. https://doi.org/10.1016/j.enpol.2012.05.054

Cagno, E., Micheli, G. J. L., \& Di Foggia, G. (2018). Smart metering projects: an 
interpretive framework for successful implementation. International Journal of Energy Sector Management, 12(2), 244-264. https://doi.org/10.1108/IJESM-082017-0009

Cassetta, E., Marra, A., Pozzi, C., \& Antonelli, P. (2017). Emerging technological trajectories and new mobility solutions. A large-scale investigation on transportrelated innovative start-ups and implications for policy. Transportation Research Part A: Policy and Practice, 106, 1-11. https://doi.org/10.1016/J.TRA.2017.09.009

Chesbrough, H. (2010). Business model innovation: Opportunities and barriers. Long Range Planning, 43(2-3), 354-363. https://doi.org/10.1016/j.lrp.2009.07.010

Chiyangwa, T. B., \& Alexander, (T.)P.M. (2016). Rapidly co-evolving technology adoption and diffusion models. Telematics and Informatics, 33(1), 56-76. https://doi.org/10.1016/j.tele.2015.05.004

Christidis, P., \& Focas, C. (2019). Factors affecting the uptake of hybrid and EVs in the European Union. Energies, 12(18), 3414. https://doi.org/10.3390/en12183414

Couper, M. P. (2008). Designing effective Web surveys. New York: Cambridge University Press.

da Silva, R. E., Sobrinho, P. M., \& de Souza, T. M. (2018). How can energy prices and subsidies accelerate the integration of EVs in Brazil? An economic analysis. The Electricity Journal, 31(3), 16-22. https://doi.org/10.1016/J.TEJ.2018.03.007

Daina, N. (2020). Private e-mobility vs e-fleet: fixing the public charging infrastructure paradox. Focus, 122. https://www.oxfordenergy.org/wpcms/wpcontent/uploads/2020/o7/OEF122.pdf

Degirmenci, K., \& Breitner, M. H. (2017). Consumer purchase intentions for EVs: Is green more important than price and range?. Transportation Research Part D: Transport and Environment, 51, 250-26o. https://doi.org/10.1016/j.trd.2017.01.001

Di Foggia, G., \& Beccarello, M. (2018). Improving efficiency in the MSW collection and disposal service combining price cap and yardstick regulation: The Italian case. Waste Management, 79, 223-231. https://doi.org/10.1016/j.wasman.2018.07.040 
Di Foggia, G., \& Lazzarotti, V. (2014). Assessing the link between revenue management and performance: insights from the Italian tourism industry. Measuring Business Excellence, 18(1), 55-65. https://doi.org/10.1108/MBE-11-2013-0059

Dillon, A., Hagerman, S., Swartout, B. and Engel, C. (2020), EV Customer Engagement: Enabling Benefits for Utilities, Customers, and Society. Natural Gas \& Electricity, 36: 1-11. https://doi.org/10.1002/gas.22173

Egnér, F., \& Trosvik, L. (2018). Electric vehicle adoption in Sweden and the impact of local policy instruments. Energy Policy, 121, 584-596. https://doi.org/10.1016/J.ENPOL.2018.06.040

Gärtner, C., \& Schön, O. (2016). Modularizing business models: between strategic flexibility and path dependence. Journal of Strategy and Management, 9(1), 39-57. https://doi.org/10.1108/JSMA-12-2014-0096

Giansoldati, M., Rotaris, L., Scorrano, M., \& Danielis, R. (2020). Does electric car knowledge influence car choice? Evidence from a hybrid choice model. Research in Transportation Economics, 100826. https://doi.org/10.1016/j.retrec.2020.100826

Giones, F., Brem, A., \& Berger, A. (2019). Strategic decisions in turbulent times: Lessons from the energy industry. Business Horizons, 62(2), 215-225. https://doi.org/10.1016/J.BUSHOR.2018.11.003

Globisch, J., Dütschke, E., \& Schleich, J. (2018). Acceptance of electric passenger cars in commercial fleets. Transportation Research Part A: Policy and Practice, 116(March), 122-129. https://doi.org/10.1016/j.tra.2018.06.004

Globisch, J., Dütschke, E., \& Wietschel, M. (2018). Adoption of EVs in commercial fleets: Why do car pool managers campaign for BEV procurement?. Transportation Research Part D: Transport and Environment, 64, 122-133. https://doi.org/10.1016/j.trd.2017.10.010

Govindan, K., Rajendran, S., Sarkis, J., \& Murugesan, P. (2015). Multi criteria decision making approaches for green supplier evaluation and selection: a literature review. Journal of Cleaner Production, 98, 66-83. https://doi.org/10.1016/j.jclepro.2013.06.046 
Hastings, S. L. (2010). Triangulation. In Encyclopedia of Research Design (pp. 15381541). Sage Publications. https://doi.org/10.4135/9781412961288

Hawkins, T. R., Singh, B., Majeau-Bettez, G., \& Strømman, A. H. (2013). Comparative Environmental Life Cycle Assessment of Conventional and Electric Vehicles. Journal of Industrial Ecology, 17(1), 53-64. https://doi.org/10.1111/j.15309290.2012.00532.x

IEA (2017). The Future of Trucks: Implications for energy and the environment (2nd ed.). Paris: International Energy Agency.

Jin, L., \& Slowik, P. (2017). Literature review of EVs consumer awareness and outreach activities (No. 03). Retrieved from https://www.theicct.org/sites/default/files/publications/Consumer-EVAwareness_ICCT_Working-Paper_23032017_vF.pdf

Junquera, B., Moreno, B., \& Álvarez, R. (2016). Analyzing consumer attitudes towards EVs purchasing intentions in Spain: Technological limitations and vehicle confidence. Technological Forecasting and Social Change, 109, 6-14. https://doi.org/10.1016/J.TECHFORE.2016.05.006

Kapustin, N. O., \& Grushevenko, D. A. (2020). Long-term EVs outlook and their potential impact on electric grid. Energy Policy, 137, 111103. https://doi.org/10.1016/j.enpol.2019.111103

Kinnear, N., Anable, J., Delmonte, E., Tailor, A., and Skippon, S. (2017). 'D2.1 Consumer attitudes and behaviours report', TRL Published Project Report PPR839, Transport Research Laboratory, Crowthorne, UK

Kougias, I., Nikitas, A., Thiel, C., \& Szabó, S. (2020). Clean energy and transport pathways for islands: A stakeholder analysis using Q method. Transportation Research Part D: Transport and Environment, 78, 102180. https://doi.org/10.1016/j.trd.2019.11.009

Kougias, I., Szabó, S., Nikitas, A., \& Theodossiou, N. (2019). Sustainable energy modelling of non-interconnected Mediterranean islands. Renewable Energy, 133, 930-940. https://doi.org/10.1016/j.renene.2018.10.090

Krupa, J. S., Rizzo, D. M., Eppstein, M. J., Brad Lanute, D., Gaalema, D. E., Lakkaraju, K., 
\& Warrender, C. E. (2014). Analysis of a consumer survey on plug-in hybrid EVs. Transportation Research Part A: Policy and Practice, 64, 14-31. https://doi.org/10.1016/J.TRA.2014.02.019

Lebeau, P., Macharis, C., Van Mierlo, J., \& Lebeau, K. (2015). Electrifying light commercial vehicles for city logistics? A total cost of ownership analysis. European Journal of Transport and Infrastructure Research, 15(4), 551-569. Retrieved from https://d1rkab7tlqy5f1.cloudfront.net/TBM/Over faculteit/Afdelingen/Engineering Systems and Services/EJTIR/Back issues/15.4/2015_04a_03 Electrifying light commercial vehicles.pdf

Li, W., Long, R., Chen, H., \& Geng, J. (2017). A review of factors influencing consumer intentions to adopt battery EVs. Renewable and Sustainable Energy Reviews, 78, 318-328. https://doi.org/10.1016/j.rser.2017.04.076

Marletto, G. (2014). Car and the city: Socio-technical transition pathways to 2030. Technological Forecasting and Social Change, 87, 164-178. https://doi.org/10.1016/J.TECHFORE.2013.12.013

McHenry, M. P. (2013). Technical and governance considerations for advanced metering infrastructure/smart meters: Technology, security, uncertainty, costs, benefits, and risks. Energy Policy, 59, 834-842. https://doi.org/10.1016/j.enpol.2013.04.048

Mueller, C. W. (2004). Conceptualization, Operationalization, and Measurement. In M. S. Lewis-beck, A. Bryman, \& T. F. Liao (Eds.), The SAGE Encyclopedia of Social Science Research Methods (pp. 162-166). Thousand Oaks. https://doi.org/http://dx.doi.org/10.4135/9781412950589.n150

Nie, Y.(M.), Ghamami, M., Zockaie, A., \& Xiao, F. (2016). Optimization of incentive polices for plug-in EVs. Transportation Research Part B: Methodological, 84, 103-123. https://doi.org/10.1016/J.TRB.2015.12.011

Pinto, B., Barata, F., Soares, C., \& Viveiros, C. (2020). Fleet Transition from Combustion to Electric Vehicles: A Case Study in a Portuguese Business Campus. Energies, 13(5), 1267. https://doi.org/10.339o/en13051267

Qiu, Y., Wang, Y. D., \& Wang, J. (2015). Implied discount rate and payback threshold of 
energy efficiency investment in the industrial sector. Applied Economics, 47(21), 2218-2233. https://doi.org/10.1080/00036846.2015.1005820

Rassier, D. G., \& Earnhart, D. (2015). Effects of environmental regulation on actual and expected profitability. Ecological Economics, 112, 129-140. https://doi.org/10.1016/j.ecolecon.2015.02.011

Ritala, P., Golnam, A., \& Wegmann, A. (2014). Coopetition-based business models: The case of Amazon.com. Industrial Marketing Management, 43(2), 236-249. https://doi.org/10.1016/j.indmarman.2013.11.005

Rogers, E. M. (2004). A Prospective and Retrospective Look at the Diffusion Model. Journal of Health Communication, 9(1). https://doi.org/10.1080/10810730490271449

Rubashkina, Y., Galeotti, M., \& Verdolini, E. (2014). Environmental regulation and competitiveness: Empirical evidence on the Porter Hypothesis from European manufacturing sectors. Energy Policy, 83, 288-300. https://doi.org/10.1016/j.enpol.2015.02.014

Santos, G. (2017). Road transport and CO2 emissions: What are the challenges? Transport Policy, 59, 71-74. https://doi.org/10.1016/J.TRANPOL.2017.06.007

Seign, R., Schüßler, M., \& Bogenberger, K. (2015). Enabling sustainable transportation: The model-based determination of business/operating areas of free-floating carsharing systems. Research in Transportation Economics, 51, 104-114. https://doi.org/10.1016/j.retrec.2015.10.012

Sierzchula, W. (2014). Factors influencing fleet manager adoption of EVs. Transportation Research Part D: Transport and Environment, 31, 126-134. https://doi.org/10.1016/j.trd.2014.05.022

Vehmas, J., Kaivo-oja, J., \& Luukkanen, J. (2018). Energy efficiency as a driver of total primary energy supply in the EU-28 countries - incremental decomposition analysis. Heliyon, 4(10), eoo878. https://doi.org/10.1016/j.heliyon.2018.eoo878

Walczuch, R., Lemmink, J., \& Streukens, S. (2007). The effect of service employees' technology readiness on technology acceptance. Information \& Management, 44(2), 
Wang, N., Tang, L., \& Pan, H. (2018). Analysis of public acceptance of EVs: An empirical study in Shanghai. Technological Forecasting and Social Change, 126, 284-291. https://doi.org/10.1016/J.TECHFORE.2017.09.011

Wang, N., Tang, L., \& Pan, H. (2019). A global comparison and assessment of incentive policy on EVs promotion. Sustainable Cities and Society, 44, 597-603. https://doi.org/10.1016/J.SCS.2018.10.024

Xia, D., Zhang, M., Yu, Q., \& Tu, Y. (2019). Developing a framework to identify barriers of Green technology adoption for enterprises. Resources, Conservation and Recycling, 143(October 2018), 99-110. https://doi.org/10.1016/j.resconrec.2018.12.022

Yan, S. (2018). The economic and environmental impacts of tax incentives for battery EVs in Europe. Energy Policy, 123, 53-63. https://doi.org/10.1016/J.ENPOL.2018.08.032

Yin, R. K. (2014). Case Study Research: Design and Methods (5th ed.). Thousand Oaks: Sage Publications.

Yokessa, M., \& Marette, S. (2019). A Review of Eco-labels and their Economic Impact. International Review of Environmental and Resource Economics, 13(1-2), 119-163. https://doi.org/10.1561/101.00000107

Zhang, Y., Jiang, Y., Rui, W., \& Thompson, R. G. (2018). Analyzing truck fleets' acceptance of alternative fuel freight vehicles in China. Renewable Energy, 1-8. https://doi.org/10.1016/j.renene.2018.09.016 